\title{
Fotografia documental e início do fotojornalismo
}

Lisbeth Oliveira*

\section{Resumo}

A questão do realismo na Fotografia a partir de novas reflexões teóricas como as de Philippe Dubois que, baseadas nas categorias peircianas dos signos (ícone, índice e símbolo), reconhecem o caráter indiciário da foto, antes mesmo de reconhecê-la como ícone ou símbolo. A Fotografia Documental, discussão intensificada na América dos anos 20 pelos fotógrafos da Farm Security Administration (FSA), que produziram a chamada Fotografia de Autor, e a influência dela no nascimento do Fotojornalismo mundial, também são tema deste trabalho.

Palavras-chave: Fotografia Documental, Fotojornalismo, realismo na Fotografia.

\section{Introdução}

Por longo tempo, o homem alimentou o sonho de que a Fotografia representava um "pedaço fiel da Realidade". Hoje, a tecnologia digital coloca em questionamento toda essa capacidade "de reprodução fiel da realidade" na fotografia, como afirmou o cineasta Wim Wenders em uma entrevista: ${ }^{1}$

Com o advento da imagem digital, a relação entre imagem e realidade ficou para sempre abalada. Nós nos aproximamos de uma época, aonde ninguém pode dizer se uma imagem é falsa ou verdadeira. Elas são todas bonitas, extraordinárias e fazem parte cada dia mais do mundo publicitário. Sua beleza, assim como sua verdade nos escapa. Logo elas conseguirão nos cegar.

Sem dúvida, o advento das imagens de síntese, permitindo todo o tipo de manipulação, veio colocar em questão o aspecto documental

* Jornalista, Mestre em Ciência da Comunicação pela Universidade de VienaÁustria, professora da Faculdade de Comunicação e Biblioteconomia da UFG. E-Mail: lisbeth@facomb.ufg.br 
na fotografia, mas não podemos esquecer que outros fatores, desde o invento fotográfico, influenciariam na afirmação de força e fidelidade do documento fotográfico. Esses dizem respeito diretamente às condições e critérios de sua produção.

Nesse aspecto, é importante conhecer a resposta a certas perguntas, tais como: Quem fez, quando e como aquela foto? A que contexto histórico refere-se aquela fotografia ? Tais questões, externas à foto, contribuem contudo no sentido de re-apresentar uma determinada realidade social já passada. Aliada a esses elementos, é de fundamental importância uma reflexão crítica sobre a figura do fotógrafo/ documentarista e sua influência no registro fotográfico, assim como questões de recepção da fotografia por parte do observador/leitor, como também uma análise sobre a pretensão de objetividade do ato fotográfico.

\section{Um olhar no passado}

Apesar do termo "Fotografia Documental" somente a partir dos anos 30 ter começado a ser usado como o é hoje, pode-se reconhecer, desde a invenção da Fotografia, fotos que poderiam ser classificadas como "fotografias documentais". Um dos exemplos mais antigos de "fotografia documental pura" é a série fotográfica de Eadweard Muybridge, que registrou em série um cavalo galopante, em 1887.

Principalmente quando os fotógrafos passaram a trabalhar fora dos ateliês, graças aos avanços técnicos da fotografia, surgiram inúmeros documentos fotográficos de cunho social marcante, como bem lembra Hannes Haas ${ }^{2}$ :

as imagens de Charles Negré, que a partir de 1852 fotografou o bairro de trabalhadores parisienses e seu asilo de inválidos em 1860; as fotografias dos meninos de rua em Londres por volta de 1860 de Oscar Rejlander; as imagens de ruas parisiense, cafés e pátios antigos feitas por volta de 1898 por Eugène Atget; as imagens , feitas a partir de 1906 por André Kertész da vida de pequenos povoados nos arredores de Budapest; as favelas novaiorquinas que Jacob Riis retratou a partir de 1877; as imagens de Arnold Genthe, que por volta de 1906 fotografou o terremoto de São Francisco, o incêndio causado e os sobreviventes em busca de seus pertences perdidos entre os escombros; as imagens de Lewis Hine, que por 


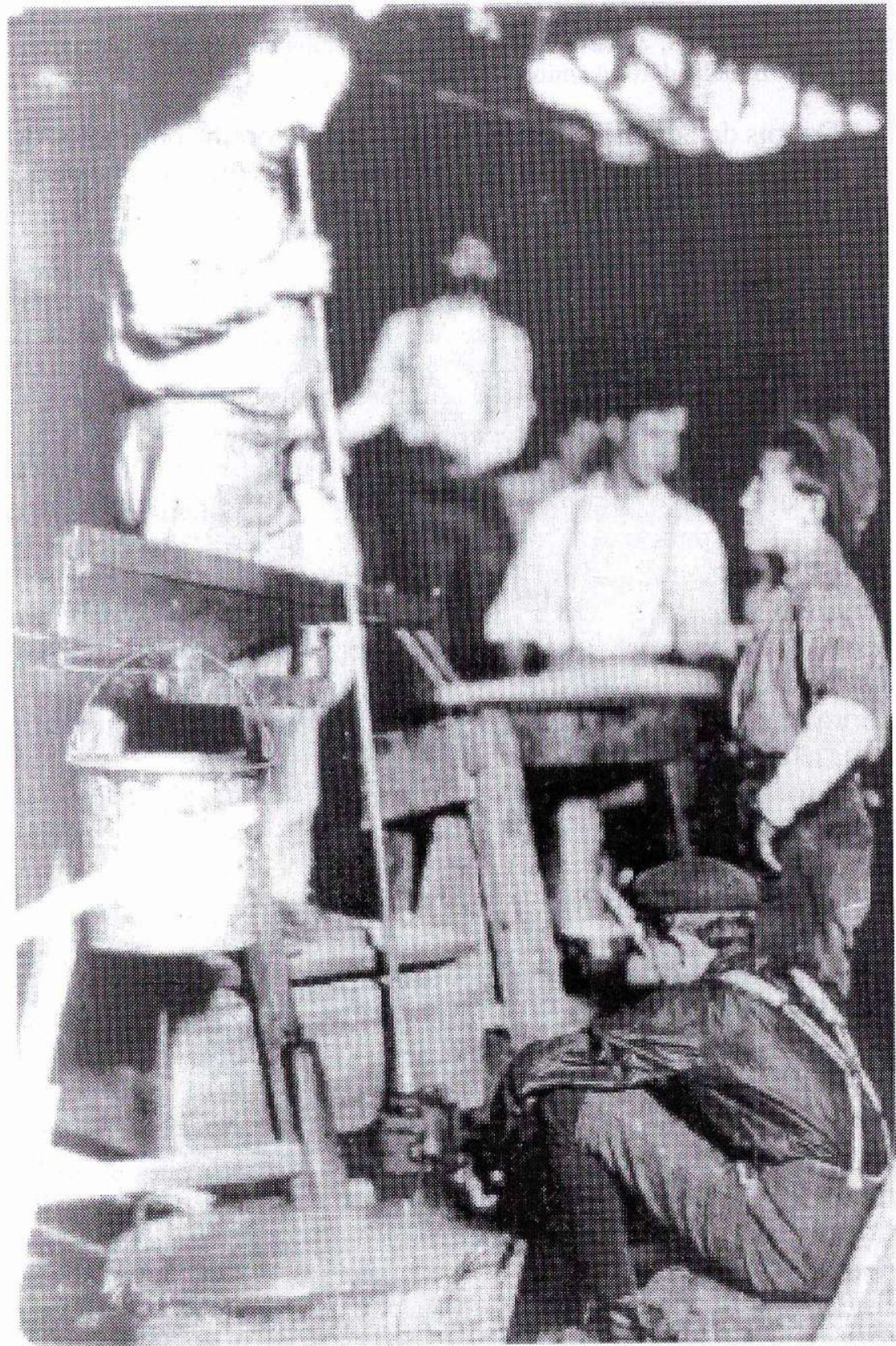

Foto 1: Lewis Wickes Hine (1874-1940) “Fábrica de Vidro”, 1908.

Comun. Inf., v.2, n. 1, p.63-77, jan./jun. 1999 
volta de 1903 fotografou a miséria social em Nova York e mais tarde, em 1908, as circunstâncias de vida, trabalho e sobrevivência dos trabalhadores de minas. (Foto 1).

Depois da Segunda Guerra Mundial, o panorama dos meios de comunicação sofre uma reestruturação, percebida principalmente no rádio, cinema e na Fotografia ${ }^{3}$,

que agora conseguem impor pelas suas capacidades e funções técnicas específicas, novos padrões de interpretação, marcados por impressões visuais e acústicas voltadas para a exatidão e rapidez. Esses meios viabilizaram uma cobertura jornalística rápida e exigiram com isso uma nova definição do termo "Atualidade".

Essas inovações no desenvolvimento dos meios de comunicaçãoe o contexto histórico-cultural conseguem, ao lado da maturidade técnica, o milieu ideal para o nascimento da fotografia de reportagem. Já nos anos 30, a Fotografia Documental vivia a sua Idade de Ouro, quando surgiram revistas ilustradas como a Life, a Vu etc, as câmeras de pequeno formato e quando a Kodak começava a desenvolver novos filmes. A imprensa, naquele momento, não oferecia apenas a informação escrita e a fotografia passava a ser considerada uma autêntica arma na transmissão da informação.

Naquele tempo, fotógrafos engajados viajaram o mundo e impressionaram a Humanidade com suas imagens, que não apenas documentavam o atual, mas que ajudavam a "construir" a história fotograficamente, o que vem significar um novo padrão de qualidade na cobertura jornalística, contribuindo assim para uma nova compreensão da história contemporânea.

Muitas das famosas e importantes fotos de imprensa desse tempo foram feitas pelos fotógrafos da Magnum. A Agência de Fotografias Magnum Photos Inc. foi fundada em 1947, em Paris, com o objetivo de "preservar a liberdade artística dos fotógrafos de imprensa e lhes garantir o controle sobre os direitos de suas imagens"'4 A geração fundadora da Magnum - Robert Capa (André Friedmann), Henri Cartier-Bresson, David Seymour (conhecido como Chim) e George Rodger - publicava já desde os anos 30, fotos que noticiavam a beleza e o terror, as guerras e as catástrofes, os acontecimentos e as emoções deste século e contribuíram, com isso, para uma melhor compreensão de nosso passado recente e antigo. (Fotos 2 e 3 ). 


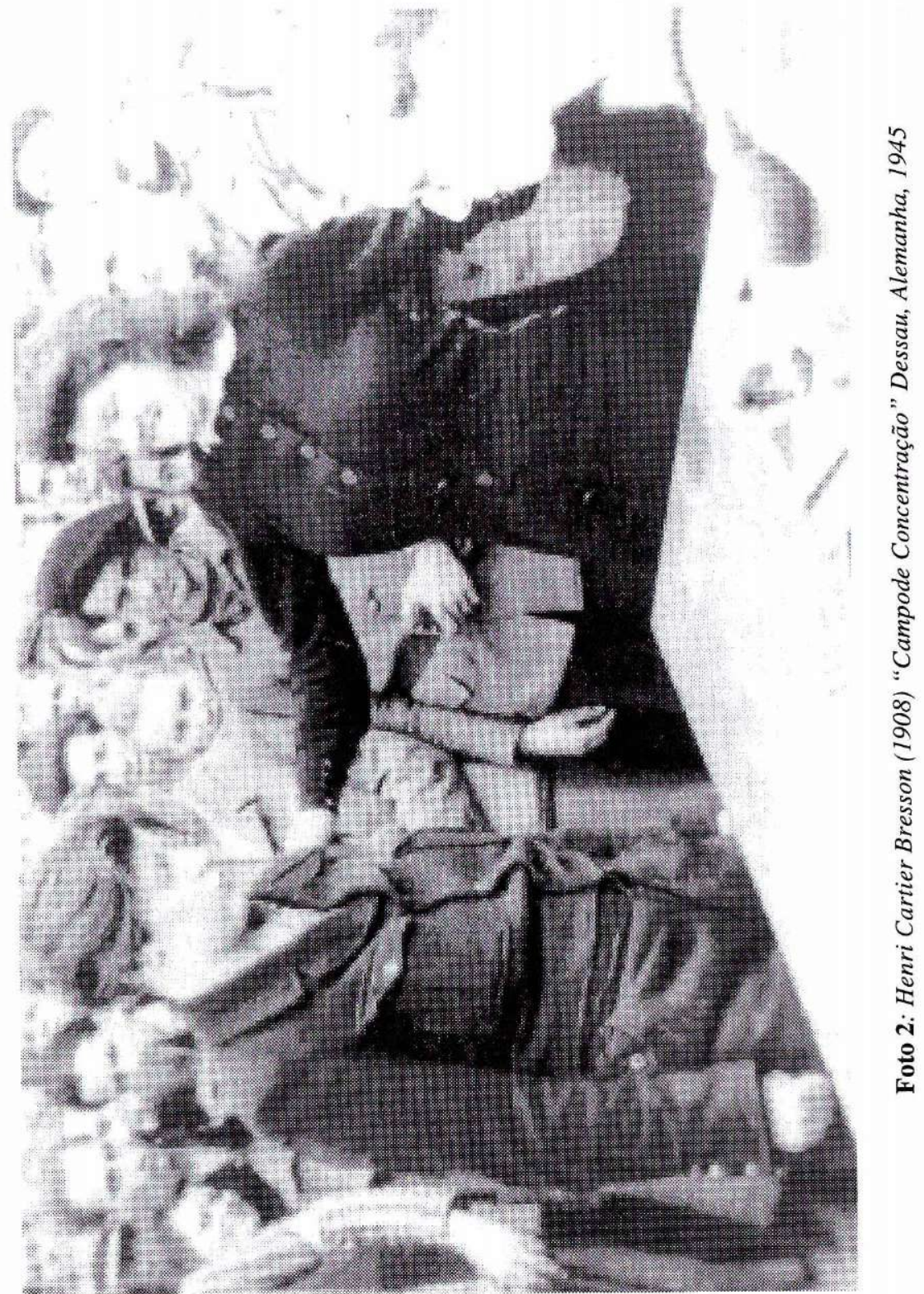

Comun. Inf., v.2, n. 1, p. 63-77, jan./jun. 1999 


\section{8}

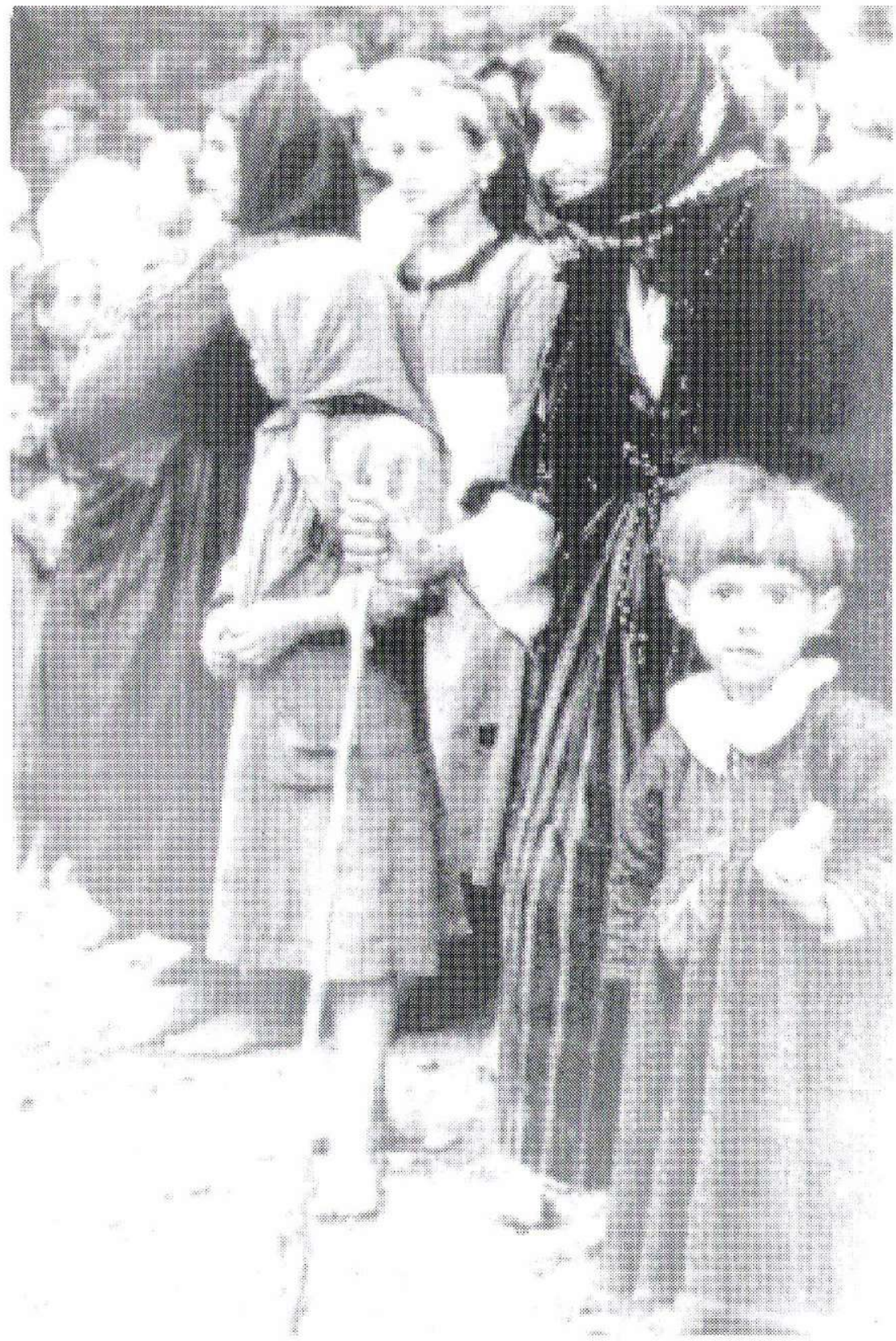

Foto 3: David Seymour (1911-1956) "Evacuation of Children", 1940

Comun. Inf., v.2, n. I, p. 63-77, jan./jun. 1999 
Depois de cinco décadas de existência, a Magnum possui hoje um abrangente acervo fotográfico de acontecimentos significativos e está sempre presente na cobertura jornalística internacional, através de renomados repórteres fotográficos, entre eles, o brasileiro Sebastião Salgado.

A contribuição dos fotógrafos da Magnum para o início do Fotojornalismo é reconhecida mundialmente. Através de suas fotos, esses fotógrafos provocaram e influenciaram discussões de temas comuns aos profissionais de imprensa do mundo todo.

Essas discussões acompanharam por longo tempo os repórteres fotográficos do Brasil. Durante minha atuação fotojornalística na imprensa brasileira, principalmente nos anos 80 , uma das questões mais intensamente discutidas entre a categoria era como nós poderíamos nos opor frente à crescente dominação da informação escrita no diaa-dia da imprensa.

Estávamos convictos de que o Fotojornalismo precisava não apenas informar rápido e ser abrangente mas, principalmente, precisava enfrentar outros desafios que surgiam, tais como, por exemplo, oferecer ao leitor a oportunidade de desenvolver sua capacidade de leitura da linguagem visual.

São desse período também várias conquistas profissionais, tais como: direito autoral, obrigatoriedade de créditos fotográficos, tabela de preços mínimos e outras. Tais conquistas colocaram os repórteres fotográficos do Brasil em posição vantajosa com relação aos seus outros colegas de imprensa.

Esse fenomenal desenvolvimento do Fotojornalismo contou, naturalmente, com a contribuição da chamada "Fotografia de Autor", como ficou conhecida a produção dos fotógrafos da Farm Security Administration (FSA), órgão criado pelo governo do Presidente Roosevelt para "proteger" a agricultura no período da crise econômica americana.

Os fotógrafos da FSA, sob a direção de Roy E. Stryker , professor da Universidade de Columbia, receberam a incumbência de reunir, no período de 1935 a 1943, uma documentação fotográfica suscetível de acordar a consciência da população norteamericana para a situação de desamparo e miséria em que se encontrava um terço da população, segundo declarações do próprio Presidente Roosevelt.

Comun. Inf., v.2, n. 1, p. 63-77, jan./jun. 1999 


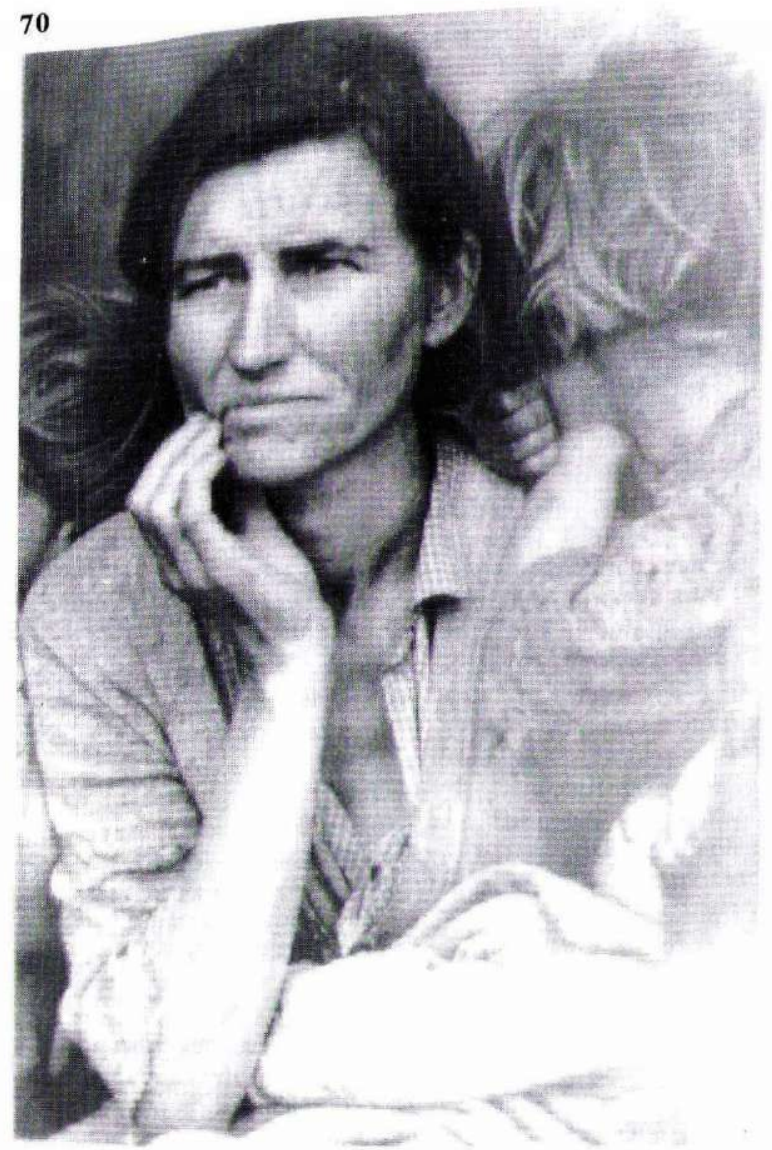

Foto 4: Dorothea Lange (1895-1965) "Mãe sem Pátria",Califórnia, 1936

Comun. Inf., v.2, n. 1, p. 63-77, jan./jun. 1999 
Walker Evans e Dorothea Lange foram os primeiros e os mais importantes a atuarem nessa missão. Outros fotógrafos, também talentosos, como Paul Taylor, Arthur Rothstein, Ben Shahn, Russel Lee, John Vachon fizeram parte da FSA, que reuniu cerca de 270.000 imagens da população afetada. (Foto 4 )

Sobre os fotógrafos representantes da "Fotografia de Autor", escreveu Klaus Honnef ${ }^{5}$ :

\begin{abstract}
Eles trouxeram à tona manifestações da realidade, tanto em conjunto como em sequência de fotos, na qual cada foto por si só refletia um universo, ao mesmo tempo que comprovava sua experiência com a realidade. Esses fotógrafos conseguiram com suas imagens uma realidade fotográfica, que é autêntica porque se prendia rigorosamente aos princípios documentais da fotografia. Uma realidade escolhida, filtrada, trabalhada e condensada pela consciência individual.
\end{abstract}

A escolha, a repetição do mesmo tema ou ponto-de-vista ou, ainda, do objeto, associadas à visão pessoal do fotógrafo, constituem marca registrada na "Fotografia de Autor". Esses engajados fotógrafos da FSA trouxeram contribuição considerável na discussão de questões teóricas da Fotografia nas décadas de 20 e 30 , questões essas que despertavam e ainda despertam interesse dentro da Fotografia.

Uma dessas questões teóricas refere-se ao aspecto documental da Fotografia. É a fotografia verdadeira, fiel à realidade que reproduz? A preocupação com a verdade, com a fidelidade, com a questão do realismo norteia o Fotojornalismo sério e comprometido com a verdade dos fatos ainda hoje e suscita novas reflexões teóricas, como abordaremos mais adiante.

\title{
Fotografia documental: definições
}

Entre as diversas definições do termo "Fotografia Documental", algumas contraditórias entre si, predomina a preocupação com a verdade:

Hans Brög ${ }^{6}$ diz que a fotografia pode ser falsa ou verdadeira, dependendo da mensagem implícita que se the atribuir. 
$\mathrm{Kulessa}^{7}$, no entanto, apela para o papel do observador/leitor, que somente pode interpretar tal mensagem como de fato sendo verdadeira ou falsa, dita corretamente ou não, com a ajuda de fotos que contenham informações iconográficas em conexão com o seu conhecimento pessoal, sua visão de mundo. Para ele, a fotografia em si "não é verdadeira nem falsa, nem certa, nem errada, nem diz a verdade e muito menos mente".

Giséle Freund ${ }^{8}$ coloca em outras palavras o que A. Bazin já havia constatado anteriormente, que a fotografia tem a

capacidade de reproduzir com tamanha fidelidade o mundo exterior, uma capacidade advinda de sua técnica, o que outorga a ela um caráter documental e a coloca como o mais exato e íntegro processo de registro da vida social.

Segundo Roy Emerson Stryker ${ }^{9}$, a fotografia é verdadeira e objetiva. Ele chama "pictorial document" o prolongamento da fotografia para fins documentários-sociais. Para ele, somente a Fotografia tem a possibilidade de uma combinação de sucesso entre atualidade, autenticidade e estética. Ele define da seguinte maneira, uma foto documental:

When you get a chance, take a few more shots of sod-houses, but please take them more from a documentary standpoint. The pictures you have taken are very excellent but do not show sufficiently well the texture and method of construction. What about some inside shots in these houses it possible".

Roland Barthes ${ }^{10}$ julga a fotografia em geral como sendo "não verdadeira" porque ela nunca poderia mostrar a essência do fotografado. Ela veicula apenas uma conhecida afinidade com o mundo visível, roubando uma identidade que ela nunca poderia ter.

Nesta linha seguem-se também reflexões mais recentes como as de Philippe Dubois ${ }^{11}$, que em sua obra faz uma retrospectiva histórica sobre a questão do realismo na Fotografia, mostrando diferentes posições que defendem o princípio de realidade próprio da relação da imagem fotoquímica com seu referente. Segundo ele, esse percurso se articula em três tempos:

Comun. Inf., v.2, n. I, p. 63-77, jan./jun. 1999 


\section{A Fotografia como espelho do real (o discurso da mimese)}

O efeito de realidade ligado à imagem fotográfica foi o princípio atribuído à semelhança existente entre a foto e seu referente. De início, a fotografia só é percebida pelo olhar ingênuo como um "analogon" objetivo do real, quando ela parece mimética por essência. A foto é concebida como espelho do mundo. É um ícone no sentido de Charles S. Peirce ${ }^{12}$.

Esse primeiro discurso (Séc. XIX) se baseia ora na denúncia, ora no elogio: Baudelaire, Hipolyte Taine, e prossegue ainda no século $\mathrm{XX}$, com duas reflexões que se inscrevem no prolongamento das concepções sobre a essência mimética da foto: "Ontologia da Imagem Fotográfica", de André Bazin (1945) e "A Mensagem Fotográfica", de Roland Barthes (1961).

\section{A Fotografia como transformação do real (o discurso do código e da desconstrução)}

O princípio da realidade foi então designado como pura "impressão", um simples "efeito". A imagem fotográfica não é um espelho neutro, mas um instrumento de transposição, de análise, de interpretação e até de transformação do real, como a língua, por exemplo, e, assim, também culturalmente codificada. A fotoé aqui um conjunto de códigos, um símbolo nos termos peircianos.

Um séquito de discursos aponta para o desenvolvimento de diversas atitudes que vão todas no sentido do deslocamento do poder de verdade, rumo a uma ancoragem na própria mensagem (a foto vai se tornar reveladora da verdade interior): Chistian Metz, Umberto Eco, Roland Barthes, René Lindekens, Rudolf Arnheim, Siegfried Kracauer, e os de caráter ideológico como Hubert Damisch, Pierre Bourdieu, Jean-LouisBaudry e os Cahiers du Cinéma.

\section{A Fotografia como traço de um real (o discurso do índice e da referência)}

Esta maneira de abordar a questão do Realismo em foto marca um certo retorno ao referente, mas livre da obsessão do ilusionismo mimético. 


\section{4}

Movimento de desconstrução (semiológica) e de denúncia (ideológica), mostrando que algo diferencia a imagem fotográfica dos outros modos de representação, um sentimento de realidade incontornável do qual não conseguimos nos livrar.

Para Dubois, é preciso prosseguir a análise, ir além da simples denúncia do "efeito do real"; deve-se interrogar segundo outros termos a ontologia da imagem fotográfica.

É nesse caminho que as reflexões teóricas recentes de Philippe Dubois a respeito da Fotografia somam-se a outras mais, quando, apoiadas na categoria de signos de Charles S. Peirce, em particular na noção de índice (por oposição a ícone e símbolo), revelam a noção peirciana inscrita em um projeto global.

Nele, a passagem da categoria de ícone à de índice não só é considerada um marco histórico na Modernidade, mas também como um deslocamento teórico, onde uma estética (clássica) da mimese, da analogia e da semelhança (a ordem da metáfora) cederia espaço a uma estética do traço, do contato, da contigüidade referencial (a ordem da metonímia), como afirma o próprio Dubois ${ }^{13}$.

É que a fotografia, antes de qualquer outra consideração representativa, antes mesmo de ser uma imagem que reproduz as aparências de um objeto, de uma pessoa ou de um espetáculo do mundo, é em primeiro lugar, essencialmente, da ordem da impressão, do traço, da marca e do registro.

Essas novas teorias, considerando a foto como precedente da ordem do índice (representação por contigüidade física do signo com o seu referente) traz uma concepção que se distingue claramente das duas outras precedentes, que colocaram sucessivamente seu objeto naquilo que Peirce chamou, em primeiro lugar, a ordem do ícone (representação por semelhança) e, em seguida, a ordem do símbolo (representação por convenção geral).

Tal concepção caracteriza-se pelo fato de ela implicar que a imagem indiciária é dotada de um valor todo singular ou particular, pois determinado unicamente por seu referente e só por este: traço de um real.

Isso traz elementos para uma nova compreensão da imagem fotográfica. A crença cega na capacidade da foto de "reproduzir a realidade com tamanha fidelidade", uma exigência da foto documental,

Comun. Inf., v.2, n. I, p. 63-77, jan./jun. 1999 
vai ser somada a uma discussão sobre o caráter indiciário da fotografia, ou seja, ao fato de que uma foto só depois de ser índice é que pode tornar-se parecida (ícone) ou adquirir significado (símbolo).

\begin{abstract}
The question of the realism on photography from new theorie reflexions as Philippe Dubois, that based on Peirce's work about signs (icon, index and simbol), shows the index character of the photo, before know it as a icon or simbol. The Documentary Photography, intense discussed at 20's on America by the photographers from Farm Security Administration (FSA), that produced the "Author's Photography" and the influence of it on the early Photojornalism around the work, all these themes are part of this work.
\end{abstract}

Key words: Documentary Photography, Photojornalism, realism on Photography.

\title{
Notas
}

1. Trecho citado por Jacques Clayssen em Digitale ( $R$-) Evolution, p. 75 do catálogo da Exposição Fotográfica Fotografie nach der Fotografie (KremsÁustria, 17.02 a 24.03.1996). Tradução da autora.

2. HAAS, Hannes. Die Fotomethapher in der Reportagediskussion - Ein Beitrag zu Genretheorie und Genrekunde. In: BOBROWSKY, Manfred, DUCHKOWISCH, Wolfgang, HAAS, Hannes. Medien und Kommunikationsgeschichte: ein Textbuch zur Einführung. Wien: W. Bräumäller, 1992, s. 157.

3. Id.ibid., p. 158

4. MANCHESTER, William (org.). Zeitblende: Fünf Jahrzehnte MagnumPhotographie. München: Schirmer/Mosel, 1989.

5. HONNEF, Klaus. Thesen zur Autorenfotografie. In: KEMP, Wolfgang. Theorie der Fotografie III 1945-1980, s. 209

6. Apud KULESSA, Detlef, In: Vision und Dokumentation-Sozialdokumentarische Photographie der 30er in den USA: eine ikonologische Betrachtung. Frankfurt am Main: Verlag Peter Lang, 1989, p. 448.

7. Id. Ibid., p. $4+48-4+49$.

8. FREUND, Gisćle. Photogruphie und Gesellschaft. Reinbek bei Hamburg: Rowohlt Taschenbuch Verlag GmbH, 1986, p. 6.

9. STRYKER, Roy E., LOCKE, Edwin. Documentary Photography. Apud KULESSA, op. cit.

10. ROLAND, Barthes. A câmera clara. S. Paulo: Nova Fronteira, 1984.

11. PHILIPPE, Dubois. O ato fotográfico. Campinas: Ed. Papirus, 1994.

12. PEIRCE, Charles Sanders. Semiótica e filosofia. S. Paulo: Cultrix, 1974. 13. Op. cit., p. 61 .

Comun. Inf., v.2, n. 1, p. 63-77, jan./jun. 1999 


\section{Referências bibliográficas}

BARTHES, Roland. A câmera clara. São Paulo: Nova Fronteira, 1984.

BAZIN, André. Ontologia da imagem fotográfica. In: Cinema - Ensaios. São Paulo: Brasiliense, 1991.

BENJAMIM, Walter. Obras escolhidas. São Paulo: Brasiliense, 1996. v . 1: Pequena história da fotografia; A obra de arte na era de sua reprodutibilidade técnica.

BILLETER, Erika. Fotografie Lateinamerika 1860-1993 (Canto a la Realidad). Bern: Benteli Verlag, 1994.

BORDIEU, Pierre. Eine illegitime Kunst: die soziallen Gebrauchsweisen der Photographie. Frankfurt am Main: Suhrkamp, 1981.

BRÖG, Hans. Erweiterung der allgemeinen Semiotik und ihre Anwendung auf die Life-Fotografie. Kastellaun, 1979

CLAYSEN, Jaques. Digitale (R)Evolution. In: Fotografie nach der fotografie (cataloge). Krems-Österreich, 1996.

COE, Brian. Das Erste Jahrhundert der Photographie 1800-1900. Bindlach: Gondrom Verlag, 1986.

DÜBI-MÜLLER, Gertrüd. Dokumentarphotographien, Vogt Schild AG, Solothurn-Schweiz, 1984.

DUBOIS, Philippe. O ato fotográfico. Campinas: Ed. Papirus, 1994.

FABIAN, Rainer. Die Photographie als Dokument und Fälschung. München, 1976.

FELDMAN-BIANCO, Bela e LEITE, Míriam L. Moreira (Orgs.). Desafios da imagem: fotografia, iconografia e vídeo nas ciências sociais. Campinas: Ed. Papirus, 1998.

FLUSSER, Vilém. Filosofia da caixa preta. São Paulo: Hucitec, 1985.

FREUND, Gisèle. La Fotografia como documento social. Barcelona: Gustavo Gilli, 1976

GALASSI, Peter. Zwei Geschichten-amerikanische Photographie 1890-1965: Aus der Sammlung des Museums of Modern Art New York. München: Schirmer/Mosel, 1995.

GERNSHEIM, Helmut. Geschichte der Photographie, die ersten Hundert Jahre. Frankfurt, 1983.

GESER, Guntram. Roland Barthes und die Subversion des Sinns: für eine Semiologie photographischer Mythen. EIKON: Internationale Zeitschrift für Photographie \& Medienkunst. Wien: Verlag Turia \& Kant, n. 3, p. 46-51, 1992.

HAAS, Hannes, DUCHKOWITSCH, Wolfgang und BOBROWSKY, Manfred. Medien und Kommunikationsgeschichte: ein Textbuch zur Einführung. Wien: Braumäller, 1992.

HABERKORN, Heinz. Anfänge der Fotografie: Entstehungsbedingungen eines neuen Mediums. Hamburg, 1985.

HEIDTMANN, Frank. Wie finde ich photographische Informationen. Berlin, 1979.

Comun. Inf., v.2, n. I, p. 63-77, jan./jun. 1999 
HONNEF, Klaus. Aspekte gegenwärtiger Dokumentarfotografie. Köln: Rheinland Verlag, 1979.

IMAGENS: Fotografia. Campinas: Unicamp, n. 7, Maio-Ago. 1996.

JOLY, Martine. Introdução à análise da magem. Campinas: Ed. Papirus, 1996.

KASPER, Josef. Belichtung und Wahrheit: Bildreportage von der Gartenlaube bis zum Stern. Frankfurt am Main: Campus Verlag, , 1979.

KEMP, Wolfgang. Foto-Essays: zur Geschichte und Theorie der Fotografie. München: Schirmer/Mosel, 1978.

KEMP, Wolfgang. Theorie der Fotografie III 1945-1980. München, 1983.

KNOPP, Guido. Die großen Fotos des Jahrhunderts. Bilder, die Geschichte machten. München: C. Bertelsmann Verlag, 1994.

KULESSA, Detlef. Vision und Dokumentation:sozial-dokumentarische Photographie der 30er in den USA - ein ikonologische Betrachtung. Frankfurt am Main: Verlag Peter Lang, 1989.

LORENZO, Vilches. Teoria de la imagem periodistica. Barcelona: Paidós Comunicación, 1997.

MACHADO, Arlindo. A ilusão especular: introdução à fotografia. Sãqo Paulo: Brasiliense, 1984.

MADDOW, Ben. Das Bild des Menschen in der Fotografie. DuMont, 1979.

MANCHESTER, William (org.). Zeitblende: Fünf Jahrzehnte MagnumPhotographic. München: Schirmer/ Mosel, 1989.

MÜLLER, Maria. Aus der Distanz: der Blick des Photographen auf sein Objekt. Ed. Cantz, 1991.

NEUSÜSS, Floris M. Fotografie als Kunst, Kunst als Fotografie. DuMont, 1979.

OLIVEIRA, Lisbeth. Dokumentarfotografie am Beispiel des Indianervölkes der Xerente. Wien, Österreich: Institut für Publizistïk und Kommunikationswissenschaft der UNI-WIEN, 1998. 126p. Diplomarbeit. (Dissertação de Mestrado)

PICHLER, Manfred. Die Photographie als Massenmedium: Zur Funktion und Struktur der Bildsprache. . Wien, 1974. (Dissertation).

RIGELE, Georg. Sozialdokumentarische Fotografie. Wien,1987. (Dissertation).

RUCKENBAUER, Josefa. Photographie als historische Quelle mit besonderer Berücksichtigung der Pressephotographie. Wien: Dip. Arb, 1991.

SCHEURER, Hans. Die Industrialisierung des Blicks: Zur Kultur und Mediengeschichte der Fotografie. Köln, 1987.

SENGER UND ETTERLIN, Stefan. Das Foto als historische Quelle: Versuch einer methodologischen Annäherung. Berlin, 1990. 